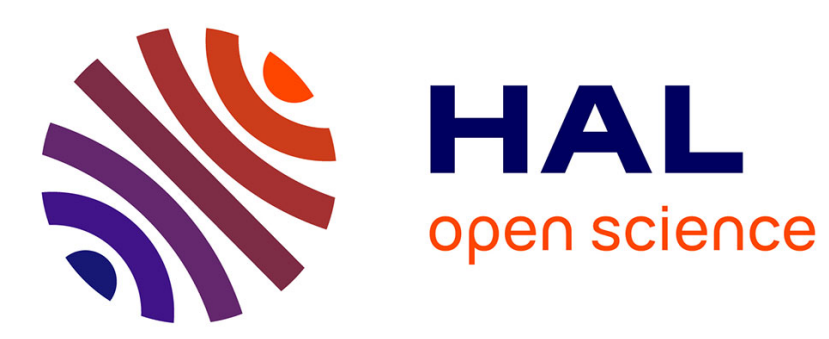

\title{
Daily embolism and refilling of root xylem vessels in three dicotyledonous crop plants
}

Corinne Buchard, Margaret Mccully, Martin Canny

\section{To cite this version:}

Corinne Buchard, Margaret Mccully, Martin Canny. Daily embolism and refilling of root xylem vessels in three dicotyledonous crop plants. Agronomie, 1999, 19 (2), pp.97-106. hal-00885917

\section{HAL Id: hal-00885917 https://hal.science/hal-00885917}

Submitted on 1 Jan 1999

HAL is a multi-disciplinary open access archive for the deposit and dissemination of scientific research documents, whether they are published or not. The documents may come from teaching and research institutions in France or abroad, or from public or private research centers.
L'archive ouverte pluridisciplinaire HAL, est destinée au dépôt et à la diffusion de documents scientifiques de niveau recherche, publiés ou non, émanant des établissements d'enseignement et de recherche français ou étrangers, des laboratoires publics ou privés. 


\title{
Daily embolism and refilling of root xylem vessels in three dicotyledonous crop plants
}

\author{
Corinne Buchard*, Margaret McCully ${ }^{* *}$, Martin Canny \\ Department of Biology, Carleton University, Ottawa, Ontario K1S 5B6, Canada
}

(Received 5 June 1998; accepted 22 December 1998)

\begin{abstract}
Embolisms were observed directly in the xylem vessels of roots of field-grown buckwheat (Fagopyrum esculentum Moench.), sunflower (Helianthus annuus L.) and soybean (Glycine max (L.) Merr.) by cryo-microscopy. No vessels were embolized at dawn, but in all three species some embolisms had formed by 0900 hours. The percentage of vessels embolized reached $40-60 \%$ between 0900 and 1200 hours, then declined to near $0 \%$ by sunset. The plants were still transpiring when embolisms were refilling. There was no correlation of percentage embolism with rate of transpiration, but a small positive correlation with balance pressure. Daily embolism and refilling of root vessels were observed previously in maize, and also appear to be a normal process in dicotyledonous crop plants. ( $($ Inra/Elsevier, Paris.)
\end{abstract}

\section{diurnal root embolism /Fagopyrum esculentum / Glycine max / Helianthus annuus / refilling-vessels}

Résumé - Cycle journalier de l'embolie et remplissage des vaisseaux du xylème des racines chez trois dicotylédones. De l'embolie a été observée par cryo-microscopie dans les vaisseaux du xylème racinaire du blé noir (Fagopyrum esculentum Moench.), du tournesol (Helianthus annuus L.) et du soja (Glycine max (L.) Merr.) cultivés en champ. Aucun vaisseau n'était embolisé à l'aube, mais pour chacune des trois espèces étudiées, l'embolie est apparue vers $9 \mathrm{~h}$. Le pourcentage de vaisseaux embolisés a atteint 40 à $60 \%$ entre 9 et $12 \mathrm{~h}$, puis est retombé à un taux presque nul avant le coucher du soleil. Les plantes transpiraient encore lorsque les vaisseaux se réemplirent. On n'a pas observé de corrélation entre le pourcentage de vaisseaux embolisés et le taux de transpiration, mais la corrélation était légèrement positive avec la pression d'équilibre. L'embolie diurne et le réemplissage des vaisseaux racinaires ont déjà été observés sur maïs et semblent être aussi un processus normal chez les plantes Dicotylédones cultivées. (® Inra/Elsevier, Paris.)

embolie diurne racinaire / Fagopyrum esculentum / Glycine max / Helianthus annuus / réparation de l'embolie

Communicated by Gérard Guyot (Avignon, France)

* Present address: École nationale supérieure agronomique de Toulouse, avenue de l'agrobiopole, Auzeville Tolosane BP 107, 31320 Castanet-Tolosan, France

** Correspondence and reprints

mmccully@ccs.carleton.ca 


\section{INTRODUCTION}

Recent studies have shown that the vessels in roots of well-watered, field-grown maize plants embolize and refill daily $[8,9,15]$. All vessels were filled at dawn, but some became embolized (gasfilled) early in the morning while shoot water potentials were still relatively high. The percentage of vessels that were embolized $(50-80 \%$ of the large-diameter late metaxylem vessels, which are responsible for carrying most of the transpiration stream) peaked mid-morning to early afternoon, often when shoot water potential values were still relatively high, and decreased during the afternoon, even though shoot water potentials were low and transpiration continued. In most cases all vessels were refilled by sunset.

This embolism and refilling of vessels in the maize roots was monitored directly by quick-freezing roots in situ while they were still attached to the plants. The frozen root pieces were examined in a cryo-scanning electron microscope (CSEM) and the number of full and embolized vessels counted. The technique provided the first direct observation of embolized vessels in roots. It also, by yielding high resolution images of the vessels and their contents, showed clearly that the refilling of the embolized vessels was by sap entering from the sides of vessels in the mature root regions examined, not basipetally along the vessels from the distant root tip.

A daily cycle of embolism and refilling of root xylem vessels has also been observed using the same freezing technique in the desert monocotyledon, Xanthorrhea preissii [14] and in wheat (McCully and Passioura, unpublished data).

Until now there has not been a similar study of embolism formation in the roots of dicotyledons. A few studies [e.g. 6, 10, 16, 17] have concluded, on the basis of hydraulic conductance measurements, that embolisms can form in the roots of several species of dicotyledonous shrubs and trees, particularly under conditions of water stress. Cotton is the only dicotyledonous crop plant in which root xylem embolisms have been reported [1]. These workers concluded that there were root vessel embolisms in droughted plants because frozen roots from these plants were more permeable to air than similarly frozen roots from well-watered plants. None of these studies of dicotyledons, all of which have detected root embolisms only indirectly, have produced any evidence for a daily cycle of embolism and refilling of vessels in the roots.

Refilling of embolized root vessels in monocotyledons is clearly necessary if each root is to continue to supply water to the shoot at a high rate to support transpiration, because no new vessels will be developed subsequently in the mature regions of these roots. The situation is of course different in dicotyledonous roots where a continual production of new secondary vessels could replace, at least in part, any which became non-functional owing to embolism formation.

Since any formation of embolisms and their refilling on a daily basis in roots of plants growing under conditions of low water stress has major implications for the understanding of the water relations of the plants, it is important to determine whether the phenomenon extends to dicotyledonous plants or is a specialised adaptation of monocotyledons only.

We report here the results of a CSEM study of the roots of buckwheat, sunflower and soybean growing under field conditions. We also discuss the implications of our findings that a significant percentage of the major conducting vessels in the roots of these plants, as in monocotyledons, embolize and refill daily.

\section{MATERIALS AND METHODS}

\subsection{Plant material}

Plants of buckwheat (Fagopyrum esculentum Moench, commercial unnamed cultivar), sunflower (Helianthus annuus L cvs Russian Mammoth and Pioneer 6322), and soybean (Glycine max (L) Merr cvs Pioneer 9008 and Maple Glen) were grown in a field plot of sandy loam soil at the Central Experimental Farm of Agriculture Canada in the summers of 1996 and 1997. Plants were 4-8 weeks old when roots were harvested at 
varying times from dawn to dusk on 12 different days in late July to mid-August. Adequate soil moisture (soil water potential, $\psi_{\text {soil }}$, around -0.05 to $-0.1 \mathrm{MPa}$ ) was maintained by irrigation when necessary.

\subsection{Water status of the sampled plants}

Leaf water potentials $\left(\psi_{\text {leaf }}\right)$ were determined with a plant water status console (pressure chamber, model 3000, Soil Moisture Corp., Santa Barbara, CA, USA). Measurements were made just prior to each time of root collection. Repeatable readings were easily obtained from the soybean and sunflower plants, but were not always reliable from the buckwheat, the petioles of which are grooved along one side. Transpiration was also measured for all plants when roots were sampled, except at dawn when the leaves were still wet. Irradiance and temperature at the leaf surface were also measured. Measurements were made with a steady state porometer (LI1600, LI-Cor Inc., Lincoln, NE, USA).

\subsection{Root selection and freezing}

Some soil was carefully pushed away from the base of the plants by hand, and the basal ends of individual mature, first-order branch roots located under the soil by gentle probing with fingers. Soil was gently removed to expose a 3- to 4-cm length of each root, which was immediately frozen as described below. Up to five roots were sequentially exposed and frozen from each plant at each time.

Freezing was with specially constructed, copperjawed cryo-pliers. These pliers could be adjusted to accommodate roots of different diameters, so that the jaws could be quickly and firmly brought into contact with a root without crushing it. The pliers were cooled in liquid nitrogen $\left(\mathrm{LN}_{2}\right)$, then quickly clamped around the exposed portion of each root. The frozen piece was then severed from the rest of the root by a scalpel run along the sides of the pliers' jaws. The piece was then transferred quickly, still held by the pliers, to a shallow container of $\mathrm{LN}_{2}$. Root pieces were placed in cryo-vials, returned to the laboratory in $\mathrm{LN}_{2}$ and stored in a cryostore. For observation, a 2- to 4-mm portion was cut from the middle of the frozen root piece under $\mathrm{LN}_{2}$ and a transverse smooth face planed with glass and diamond knives in a cryo-microtome. The planed piece was then transferred by a cryo-transfer system (CT 1500) Oxford Instruments, Eynsham, UK) to a CSEM(JEOL 6400,
JEOL Co., Tokyo, Japan). The specimen was lightly etched at $-90^{\circ} \mathrm{C}$, coated with $\mathrm{Al}$ and observed at 7 or 15 $\mathrm{kV}$. For details of these cryo-procedures see [5, 7-9]. The possibility that embolisms are produced by the freezing procedures has been discussed and eliminated $[8,9,14,15]$.

The total number of medium to large diameter vessels (diameters greater than approximately $25 \mu \mathrm{m}$ ) were counted in each transverse root face, as well as the number of these vessels that were embolized. A vessel was considered to be embolized if it contained any gas space. The vessel counts were made either directly off the microscope screen and/or from video prints. Images were also recorded on 120 roll film (Kodak TMax 100). Usually two to five roots from each plant frozen at each sampling time were examined, and the percentage of embolized vessels recorded.

\section{RESULTS}

The diameters of the branch roots selected for study varied considerably, but in the basal regions used, all included mature primary vessels and few to many mature secondary vessels. Fresh, hand-cut transverse sections of the xylem of typical root regions of each species studied are shown in figure $I A-F$. The number and diameter of xylem vessels are easily determined in such sections, but of course their contents are lost. Structural features of the xylem systems are also easily seen in the frozen roots (figures $2 A-G$ and $3 A-G$ ), but here it is possible to determine if the vessels were sap-filled, thus functioning at the time of freezing, or partially or completely embolized, thus not functioning. It is also possible in the frozen roots to detect unambiguously still-maturing vessels (the component cells, termed vessel elements, are still alive), which are not yet capable of transporting xylem sap.

Developing vessel elements have vacuole contents much richer in solutes than is the sap of mature vessels [7]. These solutes are sequestered during the freezing to form numerous electron emissive (light) lines across the vacuoles figure $2 D$ ), thus making the elements easily distinguishable from mature vessels, the frozen sap of which shows few or no sequestered solutes (e.g. figure $2 \mathrm{~A}$, $C$ and $F$ ). The youngest developing vessel elements 


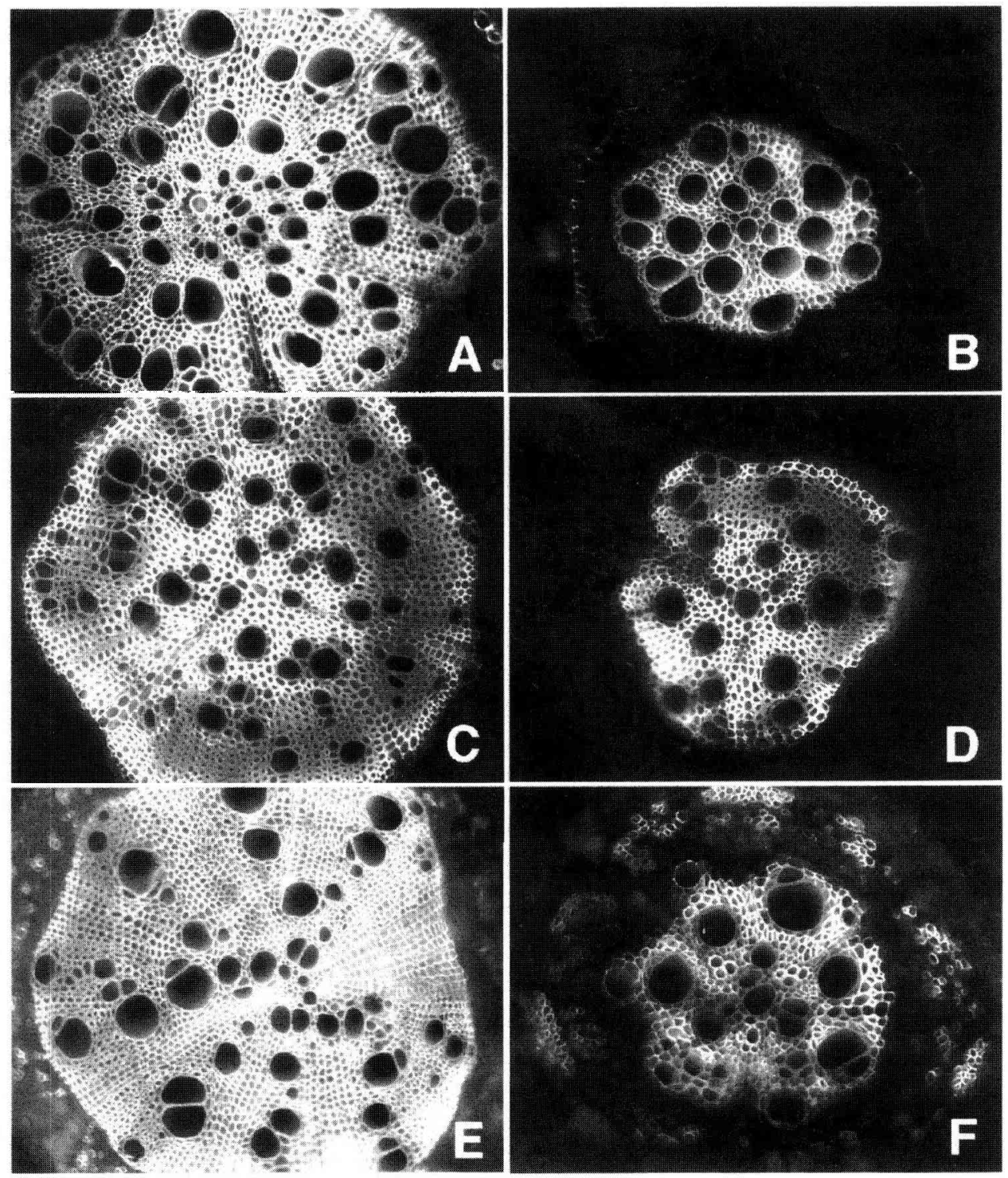

Figure 1. A-F are hand-cut sections of the mature regions of fresh, first-order branch roots with varying amounts of xylem development, typical of the range examined by cryo-microscopy. Sections were stained with aqueous thodamine B (1: 5000$)$ and viewed with fluorescence optics. A and B, buckwheat; C and D, sunflower; E and F, soybean, X 65 .

have thin peripheral walls, but later in their development the walls may be thick and lignified, while the vacuole, with its high content of solutes remains intact (figure 2D). Immature vessels were identified by these structural features and not counted. Functioning vessels were filled with frozen sap ( $f$ igures $2 A-E$, $G$ and $3 A, C-G$ ), while gas-filled spaces appeared as holes in lumens of embolized vessels (figure $2 B, E, G$ and $3 A, C-G$ ). The spaces in the embolized roots often contained debris pushed into them during the planing of the smooth transverse faces. This loose debris always built up electric charge and thus appeared light in the micrographs, so was easily identified (figures $2 B, E$ and $3 G$ ).

In all, 83 roots of buckwheat, 101 of sunflower and 89 of soybean (from 36, 37 and 35 plants, 

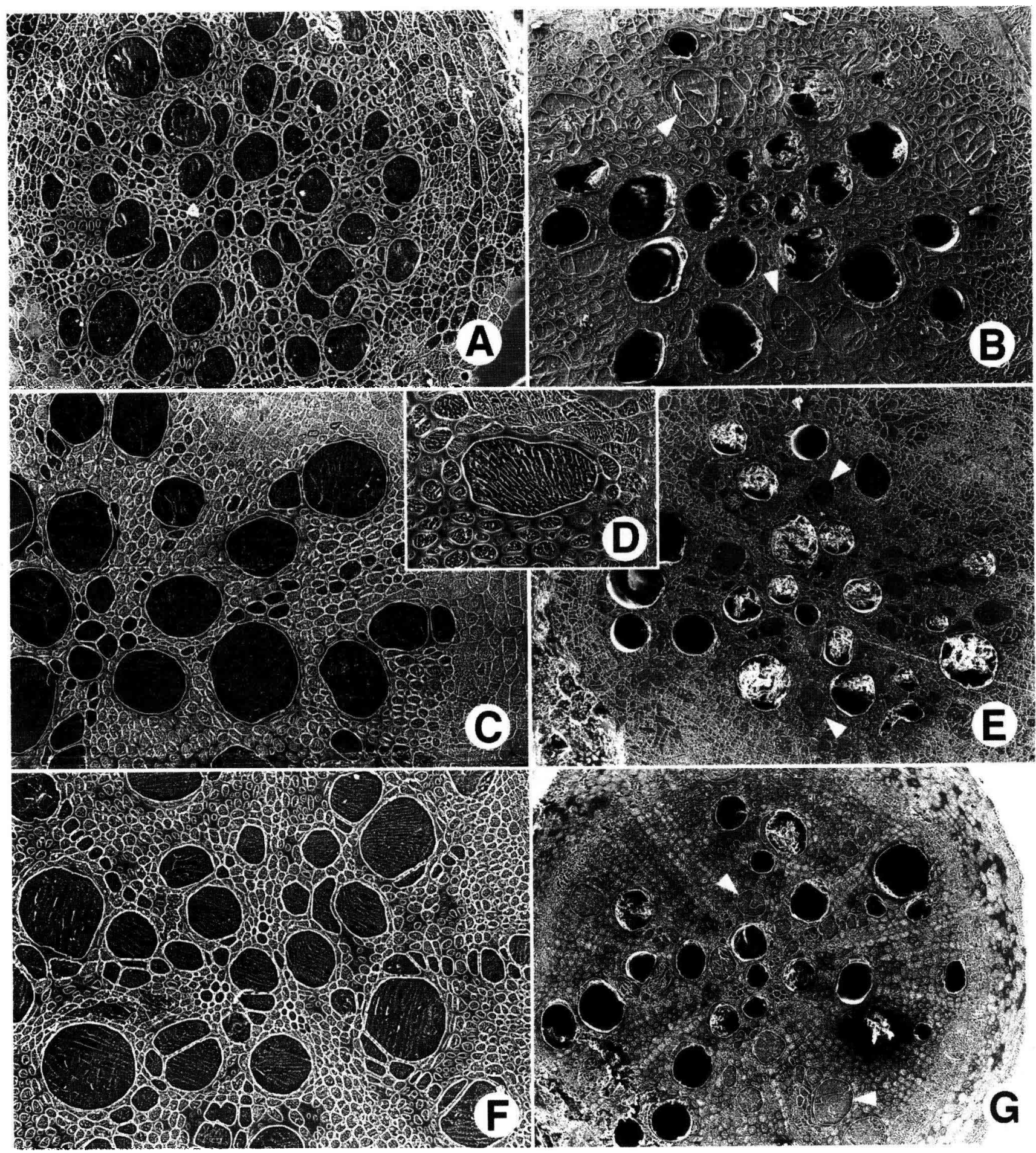

Figure 2. A-G are planed transverse faces of frozen branch roots viewed with a cryo-SEM. The time of freezing indicated for each root is Eastern Standard Time. A, C, D and F are buckwheat (0615 hours), sunflower (0650 hours) and soybean (0600 hours), respectively, in which all vessels are filled with frozen sap. B, E and G are buckwheat (0950 hours), sunflower (1600 hours) and soybean (1330 hours), respectively, each with numerous embolized vessels; D, an immature vessel elcment of sunflower. Even though this cell (D) has thick secondary walls, its vacuole is still intact and contains a high concentration of solutes as indicated by the bright lines of sequestered solute. Such immature vessels were not counted in this study. The micrographs of roots with embolized vessels were recorded at $7 \mathrm{kV}$ to minimise charging of the edges of the margins of the embolized vessels and any planing debris in them. At this low voltage and low magnification sap-filled vessels (arrowheads) are not well contrasted. Figures $A, C, D$ and $F$ were recorded at $15 \mathrm{kV}$ to contrast the frozen sap. A, $\times 150 ; \mathrm{B}, \times 180 ; \mathrm{C}, \times 290 ; \mathrm{D}, \times 80 ; \mathrm{E}, \times 80 ; \mathrm{F}, \times 150$. 


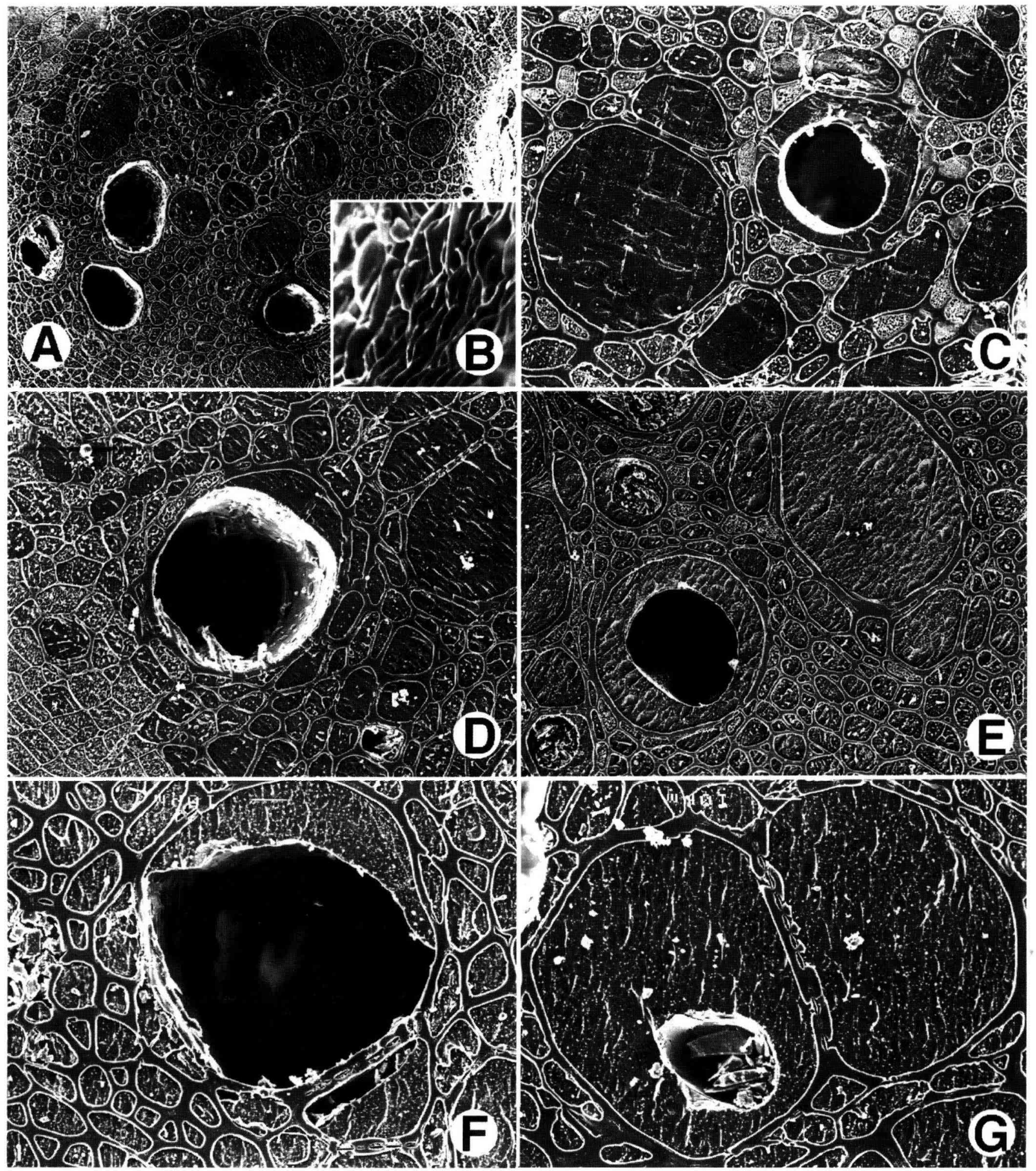

Figure 3. Preparations as in figure 2, but viewed at higher resolution. Freczing times are given for each root. All the embolized vessels shown contain some frozen sap and particularly those in roots frozen in the afternoon (when percentage of embolized vessels is decreasing) are presumed to be refilling. $\mathrm{B}$ is an enlargement of the inner surface of the largest embolized vessel in figure A. Droplets of liquid were entering the vessel through wall pits, and are probably the earliest stage of refilling. A, B and C (buckwheat, 1400 hours); D (sunflower, 11,30 hours); E (sunflower, 0830 hours); F and G (soybean, 1515 and 1530 hours, respectively). Figures recorded at $7 \mathrm{kV}$. A, $\times 170 ; \mathrm{B}, \times 3$ 500; C, ×600; D. ×380; E, ×300: F, ×620: G, ×610. 


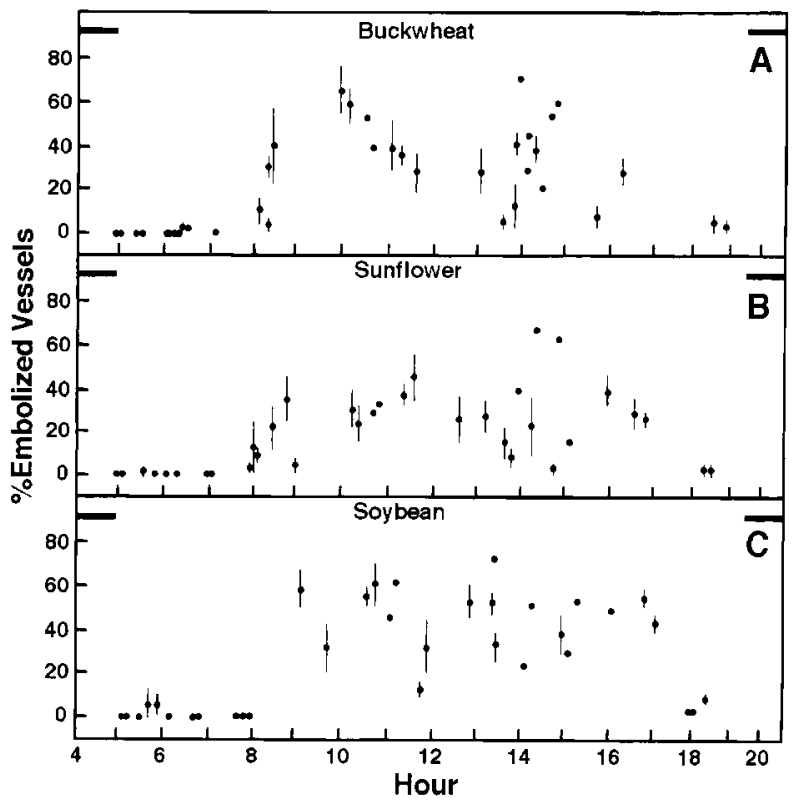

Figure 4. Percentage of vessels (of diameter greater than about $25 \mathrm{~mm}$ ) that were embolized in roots frozen at different times during the day. Points with error bars are means with standard errors for values of three to five roots. Single points are values for single roots, except for zero values in the early morning, where each point usually represents values for two or more roots. Values given for different times are for different plants. A, buckwheat; B, sunflower; C, soybean.

respectively) were examined and the percentage of vessels embolized determined for each root; figure $4 A-C$ summarises the results. In all three species all vessels in all roots examined were filled with sap at dawn, and very few embolisms were observed before 0800 hours Eastern Standard Time. Between 0800 and 0900 hours as many as a mean of $40 \%$ of the vessels were embolized in buckwheat and sunflower (soybean roots were not observed in this interval). Just after 0900 hours almost $60 \%$ of the vessels in soybean roots were embolized and mean values varied throughout the day between approximately 40 and $60 \%$ until 1700 hours when they dropped to values between 0 and $10 \%$. In buckwheat, percentage embolism reached a peak mean of just over $60 \%$, then fell fairly steadily to about $10 \%$ at 1330 hours. There was a second peak reaching about $50 \%$ by 1430 hours, then a fall to just over $0 \%$ at 1630 hours. The sunflower maintained a more steady rate between 40 and $20 \%$ until

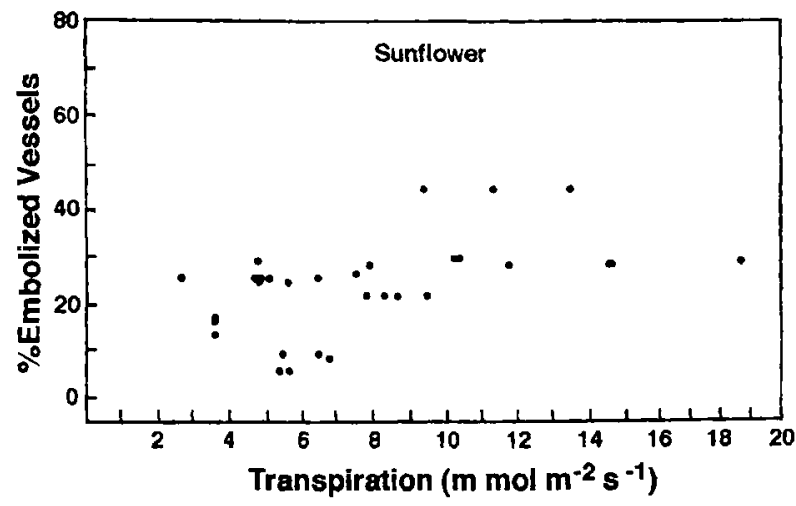

Figure 5. Graph of percentage of sunflower root vessels that were embolized as a function of transpiration rate measured close to the time that the roots were frozen. $R^{2}=0.27, N=31$.

1500 hours, but fell to close to $0 \%$ after 1800 hours. There was no difference in percentage vessel embolism among roots of different diameters (data not shown).

Throughout the day when embolisms were present at least some of these embolized vessels were partially filled with sap. It is not possible to determine for certain whether these were emptying or refilling. However, late in the afternoon, when the percentage of embolized vessels was dropping rapidly, almost all embolized vessels were partially filled and it seems reasonable to assume that these vessels were refilling with sap.

Leaf water potentials of the plants studied ranged from -0.3 to $-0.5 \mathrm{MPa}$ soon after sunrise, -0.6 to $-1.0 \mathrm{MPa}$ mid-morning, -0.7 to $-1.1 \mathrm{MPa}$ around mid-day, and -0.4 to $-1.0 \mathrm{MPa}$ at mid- to lateafternoon. Irradiance (PAR) at mid-day on sunny days ranged from 1300 to $1800 \mu \mathrm{mol} \mathrm{m}^{-2} \mathrm{~s}^{-1}$, and on cloudy days from 400 to $600 \mu \mathrm{mol} \mathrm{m} \mathrm{m}^{-2} \mathrm{~s}^{-1}$. Temperatures around mid-day ranged from a high of 36 to $23{ }^{\circ} \mathrm{C}$, with most values in the mid-20s. Transpiration at mid-day reached 11 $17 \mathrm{mmol} \mathrm{m}^{-2} \mathrm{~s}^{-1}$ for soybean and sunflower, mainly $6-11 \mathrm{mmol} \mathrm{m}^{-2} \mathrm{~s}^{-1}$ for buckwheat. By late afternoon transpiration of all three species was between 8 and $12 \mathrm{mmol} \mathrm{m}^{-2} \mathrm{~s}^{-1}$. Transpiration rates were higher at similar times on sunny compared to cloudy days, but there was no difference in percentage of embolized vessels. 
The question of the extent to which vessel embolism depended upon transpiration rate was addressed by plotting percentage embolism against measured transpiration for each species at all those times when the two measurements were made close together. The strongest positive correlation was found for sunflower, and the plot is shown in figure 5 . The value of $\mathrm{R}^{2}$ was $0.27(\mathrm{~N}=31)$. For buckwheat the correlation was non-existent $\left(R^{2}=0.003\right.$, $\mathrm{N}=28)$ and for soybean it was negative $\left(\mathrm{R}^{2}=0.33\right.$, $\mathrm{N}=24$ ). With the variance ascribable to rate of transpiration being zero in one species, $+27 \%$ in another and $-33 \%$ in the third, it is reasonable to conclude that embolism is unrelated to rate of transpiration.

Asking the same question in relation to dependence on balance pressure produces a less satisfactory answer because the number of co-temporal measurements is small. The value of $\mathrm{R}^{2}$ for soybean was $0.52(\mathrm{~N}=4)$, for buckwheat $0.48(\mathrm{~N}=7)$, and for sunflower $0.05(\mathrm{~N}=9)$. For the pooled values of all species, $\mathrm{R}^{2}=0.36(\mathrm{~N}=20)$. All were positively correlated. A weak positive dependence on balance pressure may be confirmed.

\section{DISCUSSION}

The daily embolism and refilling of vessels in the roots of the three species of herbaceous dicotyledons studied is similar to that reported for maize [8, $9,15]$ and observed also in preliminary studies of wheat (McCully and Passioura, unpublished data). In each case the plants were growing under relatively low moisture stress in the field. These findings, in such a diverse range of species, suggest that the phenomenon occurs generally in herbaceous crop plants. Similar findings in the woody desert monocotyledon, Xanthorrhea, in spring under high soil moisture, and in late summer at high temperature and irradiance [14] suggest an even more universal phenomenon.

A gas-filled vessel cannot deliver sap to the transpiration stream, nor can any vessel that is only partially empty of sap (e.g. figure $3 C-G$ ), because in the latter case the bubbles of gas would expand immediately the surrounding liquid came under tension greater than the vapour pressure of water and the vessel would again be gas-filled. The peak percentages of major conducting vessels found to be embolized (partially or entirely gas-filled) during the day in the present study (40-60\%), though somewhat lower than that found for maize (up to $80 \%$ ), still represents a loss of about half the capacity of the root xylem to deliver the transpiration stream to the shoots. This loss is actually greater because, most commonly, a higher proportion of the largest diameter vessels were embolized (e.g. figure $2 B, E, G$ ). It is these wide vessels which will carry the bulk of the transpiration stream, in accord with the Hagen Poiseuille relationship for volume flow dependence on the fourth power of the radius of a conduit [13]. (The contribution of tracheary elements of diameter $<25 \mu \mathrm{m}$ which were not counted in the present study would be relatively small for the same reason.)

Despite the loss of flow capacity by embolization, transpiration continued throughout the day and the plants were mostly not noticeably wilted at any time, so that those conduits still functioning (i.e. unembolized large-diameter vessels and small tracheary elements which rarely embolize) must have been delivering an adequate volume of water to the shoots. This suggests that the root xylem system is over built so as to compensate for the daily reduction in its flow capacity. Also, as proposed by McCully et al. [9] vessels may be continually embolizing and refilling during the day, thus reducing somewhat the apparent loss of conducting capacity as determined from the percentage of vessels embolized.

These properties of the root systems of mesophytic crop plants growing under normal field conditions are only just now being recognized because the cryo-techniques have allowed for the first time the preservation of the contents of the xylem conduits in the positions in which they were in the functioning root. Recently, Pate and Canny [14] have verified the reliability of the cryo-technique in their study of embolism of vessels in Xanthorrhea preisii. They determined the number of embolized vessels by the novel technique of measuring the volume of air that could be withdrawn from a 
known number and volume of vessels in these roots throughout the day, and at the same time pieces of the same roots were frozen for subsequent cryoexamination. The results from both techniques were in close agreement, and revealed a daily course of embolism formation and refilling similar to the one shown in the present study. The direct detection of embolisms by cryo-microscopy avoids the possible errors of conventional indirect determinations of vessel embolisms [3].

The occurrence of daily embolisms of vessels in leaves and their refilling at night in some herbaceous dicotyledons was predicted by Milburn on the basis of detection of acoustic emissions (clicks) from the leaves $[4,11,12]$. These clicks, thought to be caused by cavitation (resulting in embolism) of individual vessels (but see reservations about this interpretation [18]), were detected during much of the day, but not in the early morning. A similar daily embolism and refilling of vessels at night in the stems of field-grown maize can be inferred from results obtained by Tyree et al. [18] who used ultrasonic acoustic emissions as indicators of cavitation events. The maximum frequency of these emissions occurred in droughted plants at leaf water potentials of about $-1.7 \mathrm{MPa}$, but some were also detected in well-watered plants at about -1.0 MPa. Strangely, acoustic emissions have never been used to estimate embolism formation in roots.

Crombie et al. [4] first detected audible clicks when $\psi_{\text {leaf }}$ of two of the three dicotyledonous species measured under comparable conditions was relatively high (tomato: $-0.2 \mathrm{MPa}$, castor bean: -0.5 $\mathrm{MPa}$, plantain: $-1.7 \mathrm{MPa}$ ). These values for $\psi_{\text {leaf }}$ decreased to $-0.4,-0.8$ and $-1.9 \mathrm{Mpa}$, respectively, when $50 \%$ of total clicks from the leaves had been recorded.

These values for $\psi_{\text {leaf }}$, recorded when embolisms were presumed to be forming in the tomato and castor bean leaves in the above study, are in the same range as those we measured in early and mid-morning in the buckwheat, soybean and sunflower plants in the present study. We did not determine the values for $\psi_{\text {root }}$ in these transpiring plants, but these would generally be assumed to be higher than those measured for the corresponding leaves. Indeed, maize plants growing in the same field plot and measured under approximately the same conditions had $\psi_{\text {root }}$ about $0.2 \mathrm{MPa}$ less negative than those of leaves of the same plants [8]. Thus embolisms are forming in vessels in the roots of herbaceous plants when xylem tensions are very low.

The detection of partially embolized vessels, thought to be refilling, was first achieved using the cryo-technique with petioles of sunflower [2]. Vessels at all stages of apparent entry of sap were also seen in the maize roots $[8,9,15]$. Some of these were present at all times of the day but were much more prevalent (in the mid to late-afternoon when the number of embolized vessels was decreasing. Similar observations were made in the present study (e.g. figures $3 A-G$ ). This refilling is certainly accomplished in at most a few hours, and more likely in a much shorter time, while plants are still transpiring, and $\psi_{\text {leaf }}$ is still relatively low $(-0.4$ MPa was the lowest value recorded in the present study). The refilling of the embolized vessels appears to be driven by the same osmotic forces as 'root pressure'. Exactly how this refilling is accomplished while transpiration continues is unknown but various possibilities have been discussed elsewhere $[3,8]$.

Acknowledgements: This study was supported by operating grants to MEM and MJC from the Natural Sciences and Engineering Research Council of Canada. We thank Agriculture Canada for the use of the field plot, David Overy for maintaining this plot, Cheng Huang and Lewis Ling for help with the cryomicroscopy and Adam Baker for making the plates.

\section{REFERENCES}

[1] Byrne G.F., Begg J.E., Hansen G.K., Cavitation and resistance to water flow in plant roots, Agric. Meteorol. 18 (1977) 21-25.

[2] Canny M.J., Vessel contents during transpiration embolisms and refilling, Am. J. Bot. 84 (1997) 1223-1230.

[3] Canny M.J., Applications of the compensating pressure theory of water transport, Am. J. Bot. 85 (1998) 897-901. 
[4] Crombie D.S., Milburn J.A., Hipkins M.F., Maximum sustainable xylem sap tensions in Rhododendron and other species, Planta 163 (1985) 27-33.

[5] Huang C.X., Canny M.J., Oates K., McCully M.E., Planing frozen hydrated plant specimens for SEM observations and EDX microanalysis, Micros. Res. Technol. 28 (1994) 67-74.

[6] Kolb K.J., Sperry J.S., Lamont B.B., A method for measuring xylem hydraulic conductance and embolism in entire root and shoot systems, J. Exp. Bot. 4 (1996) $1805-1810$.

[7] McCully M.E., Accumulation of high levels of potassium in developing xylem elements in roots of soybean and some other dicotyledons, Protoplasma 183 (1994) 116-125.

[8] McCully M.E., Root xylem embolisms and refilling: Relation to water potentials of soil, roots and leaves, and osmotic potentials of root xylem sap, Plant. Physiol. 119 (1999) 1001-1008.

[9] McCully M.E., Huang C.X., Ling L.E.C., Daily embolism and refilling of xylem vessels in the roots of field-grown maize, New Phytol. 138 (1998) 327-342.

[10] Mencuccini M., Comstock J., Vulnerability to cavitation in populations of two desert species, Hymenoclea salsola and Ambrosia dumosa, from different climatic regions, J. Exp. Bot. 48 (1997) 1323-1334.
[11] Milburn J.A., Cavitation and embolisms in xylem conduits, in: A.S. Raghavendra (Ed.), Physiology of Trees, John Wiley and Sons, New York, 1991.

[12] Milburn J.A., McLaughlin M.E., Studies of cavitation in isolated vascular bundles and whole leaves of Plantago major L., New Phytol. 73 (1974) 861-871.

[13] Nobel P.S., Physicochemical and Environmental Plant Physiology, Academic Press, Boston, 1991.

[14] Pate J.S., Canny M.J., Quantitation of vessel embolisms by direct observation: a comparison of two methods, New Phytol. 141 (1999) 33-43.

[15] Shane M.W., McCully M.E., Root xylem embolisms: Implications for water flow to the shoot in large, field-grown maize plants with only one root, Aust. J. Plant Physiol. 26 (1999) 107-114.

[16] Sperry J.S., Ikeda T., Xylem cavitation in roots and stems of Douglas fir and white fir, Tree Physiol. 17 (1997) 275-280.

[17] Tsuda M., Tyree M.T., Whole-plant hydraulic resistance and vulnerability segmentation in Acer saccharinum, Tree Physiol. 17 (1997) 351-357.

[18] Tyree M.T., Fiscus E.L., Wullschleger S.D., Dixon M.A., Detection of xylem cavitation in corn under field conditions, Plant Physiol. 82 (1986) 597-599. 